\title{
RANCANG BANGUN ALAT KALIBRASI SPHYGMOMANOMETER
}

\author{
Agung Satrio Nugroho1*, Vivi Vira Viridianti ${ }^{1}$, dan Amanda Azi ${ }^{1}$ \\ Universitas Widya Husada Semarang \\ Email : agungsatrio.nugroho@yahoo.com*, Vivi.vira.viridianti@gmail.com, aziamanda00@gmail.com
}

Diterima : 5 April 2021 . Disetujui : 15 Juli 2021 . Dipublikasikan : 28 Juli 2021

\begin{abstract}
ABSTRAK
Peralatan kesehatan pada umumnya membutuhkan tingkat akurasi yang baik, sehingga perlu dilakukan kalibrasi. Salah satunya adalah alat sphygmomanometer yang digunakan untuk mengukur tekanan darah. Alat kalibrasi yang telah ada digunakan dengan membandingkan nilai tekanan raksa dengan nilai tekanan alat menggunakan pandangan mata. Cara ini berpotensi terjadi kesalahan pembacaan. Dari masalah tersebut, dibuatlah sebuah modifikasi alat sphygmomanometer yang dapat mengurangi kesalahan pembacaan tekanan. Alat ini digunakan dengan cara menekan tombol untuk menyimpan tekanan hasil kalibrasi, sementara pengguna hanya perlu melihat skala tekanan pada sphygmomanometer raksa.

Alat ini menggunakan sensor tekanan MPX5500DP dengan jangkauan tekanan $0-500 \mathrm{kPa}$. Output sensor diolah menggunakan mikrokontroler Atmega328 dan hasil pengukuran tekanan disimpan di dalam EEPROM. Hasil tersebut dipanggil kembali dan ditampilkan pada LCD Selain itu alat ini mampu menghitung kebocoran tensimeter dan menampilkan kondisi tensimeter "layak" atau "tidak layak".

Untuk mengetahui akurasi alat kalibrator ini dilakukan pengujian di Laboratorium Prodi elektromedik. Metode yang dilakukan adalah mengukur tekanan shygmomanometer air raksa menggunakan alat kalibrasi yang telah dibuat dan FLUKE DPM4 yang dilakukan secara bersamaan. Dari hasil perbandingan didapatkan hasil selisih pengukuran terhadap alat kalibrasi maksimal $0,5 \mathrm{mmHg}$, nilai tersebut masih di bawah nilai toleransi sebesar 1 mmHg. Persentase rata rata error pembacaan tekanan terhadap alat kalibrasi sebesar $0,3 \%$.
\end{abstract}

Kata kunci : tekanan, kalibrasi, sphygmomanometer, kebocoran, akurasi.

\section{ABSTRACT}

Health equipment generally requires a good level of accuracy, so it needs to be calibrated. One of them is a sphygmomanometer which is used to measure blood pressure. Existing calibration tools are used by comparing the value of mercury pressure with the value of tool pressure using eye sight. This method has the potential for reading errors. From this problem, a modification of the sphygmomanometer tool was made to reduce the error in pressure readings. This tool is used by pressing a button to store the pressure calibrated results, while the user only needs to see the pressure scale on the mercury sphygmomanometer.

This tool uses a pressure sensor MPX5500DP with a pressure range of $0-500 \mathrm{kPa}$. The sensor output is processed using the Atmega328 microcontroller and the pressure measurement results are stored in the EEPROM. The results are recalled and displayed on the LCD. In addition, this tool is able to calculate the leakage of the tensimeter and displays the condition of the tensimeter "proper" or "not feasible".

To find out the accuracy of this calibrator, tests were carried out at the Electromedical Study Program Laboratory. The method used is measuring the pressure of the mercury shygmomanometer using a calibration tool that has been made and FLUKE DPM4 which is carried out simultaneously. From the comparison, it is found that the difference between the measurement of the calibration tool is a maximum of $0.5 \mathrm{mmHg}$, this value is still below the tolerance value of $1 \mathrm{mmHg}$. The average percentage of error for the pressure reading of the calibration tool is $0.3 \%$.

Keywords : pressure, calibration, sphygmomanometer, leakage, accuracy

\section{PENDAHULUAN}

Pelayanan kesehatan yang optimal bagi masyarakat merupakan hal yang harus diperhatikan guna membentuk masyarakat Indonesia yang sehat jasmani dan rohani. Kebutuhan dan tuntutan masyarakat akan suatu pelayanan kesehatan semakin meningkat seiring dengan peningkatan pengetahuan 
dan kemampuan masyarakat, maupun perkembangan ilmu pengetahuan dan teknologi kesehatan.

Tuntutan tersebut harus didukung dengan kemajuan dan perkembangan peralatan kesehatan yang lebih efisien sehingga mutu pelayanan kesehatan dapat meningkat dengan baik. Dengan semakin meningkatnya kesejahteraan masyarakat, tuntutan pelayanan di bidang kesehatan semakin meningkat pula.

Dalam memberikan pelayanan kesehatan kepada pasien, dokter melakukan diagnosa awal untuk mengetahui keluhan penyakit pasien. Salah satu cara yang digunakan dokter untuk diagnosa awal terhadap pasien, adalah dengan mengukur tekanan darah. Untuk mengukur tekanan darah, dokter membutuhkan sphygmomanometer yang teliti dan akurat. Tingkat akurasi sphygmomanometer dapat diketahui dengan melakukan kalibrasi.

Apabila sphygmomanometer tidak akurat, maka akan terjadi salah diagnosa oleh dokter yang akan menyebabkan terjadinya kesalahan pemberian obat atau terapi.

Berdasarkan paparan diatas, maka penulis tertarik melakukan penelitian dengan judul "Rancang Bangun Alat Kalibrasi Sphygmomanometer".

Tujuan Tercipta alat kalibrasi sphygmomanometer dengan jangkauan tekanan 0$300 \mathrm{mmHg}$ yang dapat menyimpan hasil kalibrasi dan mengolah data kalibrasi untuk menentukan kelayakan sphygmomanometer.

\section{METODE PENELITIAN}

\section{Desain Penelitian}

Tahapan-tahapan perencanaan dalam pembuatan modul adalah sebagai berikut:

1. Mempersiapkan gambar rangkaian keseluruhan.
2. Menentukan komponen elektronik yang diperlukan sesuai dengan rangkaian.

3. Menentukan letak bagian-bagian yang akan dipasang pada casing, seperti sensor, rangkaian mikrokontroler, LCD, baterai, dan rangkaian panel yang berisi saklar power, tombol reset, dan tempat titik pengukuran (TP).

4. Membuat papan rangkaian dengan langkahlangkah sebagai berikut:

a. Mempersiapkan papan PCB.

b. Merancang tata letak komponen dan jalur-jalur hubungan antara komponen dan dijaga untuk menghindari hubung singkat.

c. Merancang layout rangkaian yang akan digunakan, dalam hal ini dibantu oleh komputer melalui software Eagle.

d. Hasil layout kemudian dicetak di atas kertas khusus kemudian dipanaskan pada PCB agar gambar layout tercetak permanen pada PCB.

e. Setelah hasil cetak layout telah jadi, papan PCB polos dilubangi dengan bor PCB sesuai dengan letak pin komponen yang telah dibuat.

f. Melarutkan PCB yang telah tercetak gambar layout dengan bantuan $\mathrm{FeCl}_{3}$ dan air panas.

g. Memastikan tidak ada jalur antar penghantar yang saling bersinggungan.

h. Memasang komponen yang dibutuhkan di atas papan PCB.

i. Penggunaan jumper diusahakan seminimal mungkin.

5. Men-download program yang telah dibuat ke mikrokontroler menggunakan software Arduino IDE untuk men-download program dan modul downloader untuk menghubungkan komputer dengan mikrokontroler.

6. 


\section{Perencanaan Program}
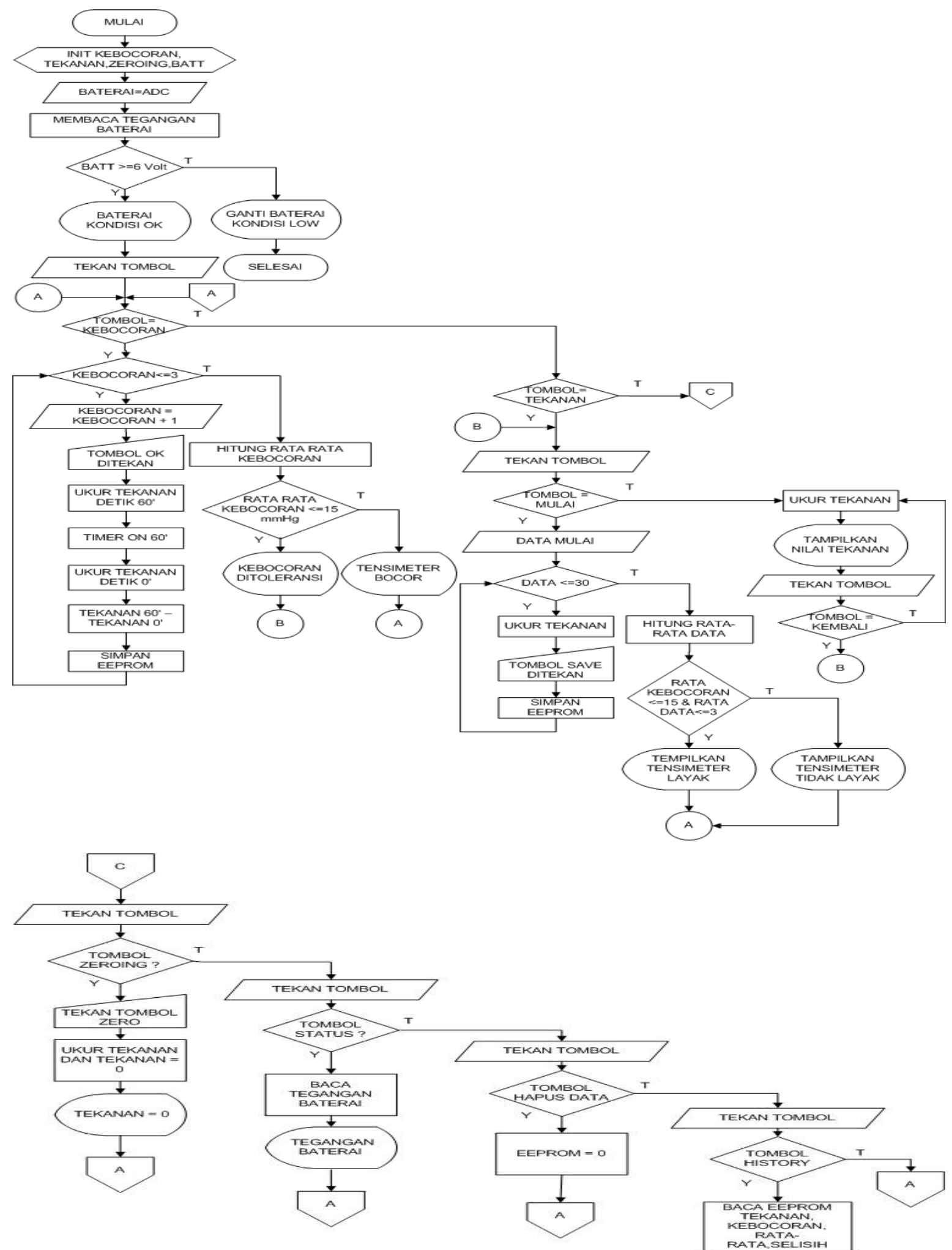

Gambar 1. Flowchart Program 


\section{Cara Kerja Alat}

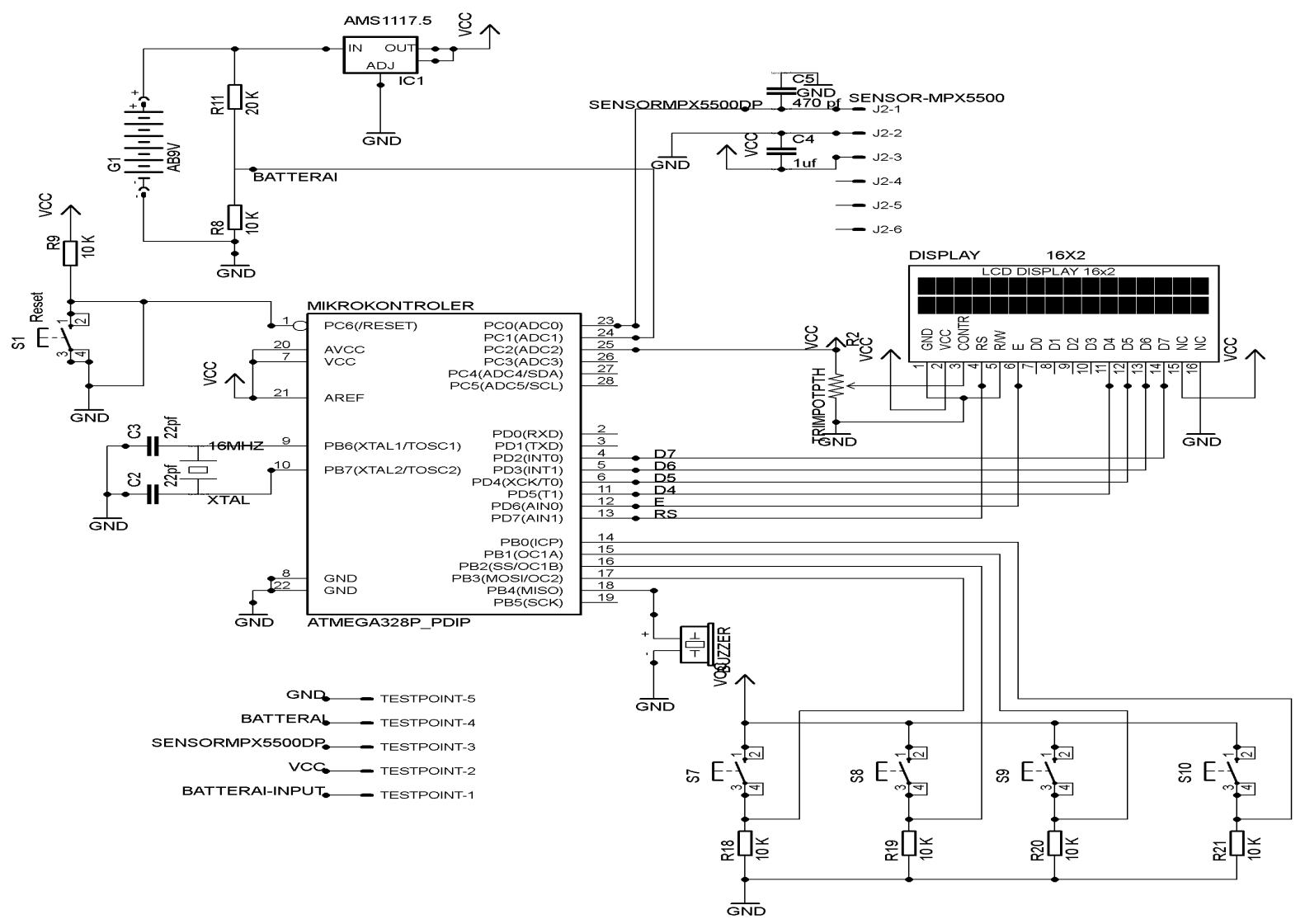

Gambar 2. Rangkaian Alat Keseluruhan

Ketika dinyalakan, tegangan $9 \mathrm{~V}$ dari baterai akan diregulasi oleh IC Voltage Regulator menjadi 5V dan memberikan daya ke sensor, rangkaian mikrokontroler, dan LCD. Dalam keadaan awal ini, mikrokontroler menginisialisasi port dan fungsinya sesuai dengan program yang telah dimasukkan, LCD akan menampilkan beberapa menu pengukuran yang akan digunakan.

Sensor Mpx5500DP memiliki karakteristik apabila tidak ada tekanan yang diberikan pada sensor output sensor sebesar $200 \mathrm{mV}$, dan sensor MPX5500DP ini satuan dasarnya berupa satuan $\mathrm{kPa}$ yang perlu dikonversikan terlebih dahulu pada koding menjadi $\mathrm{mmHg}$. Sensitifitas pada sensor ini sebesar $9 \mathrm{mV} / \mathrm{kPa}$ apabila di konversikan menjadi $\mathrm{mmHg}$ menjadi $9 \mathrm{mV}=$ $7,5 \mathrm{mmHg}$ atau $1 \mathrm{mmHg}=1,2 \mathrm{mV}$. Jika sensor menerima tekanan maka output sensor akan mengeluarkan tegangan, tegangan yang keluar pada sensor inilah yang akan di konversikan menjadi $\mathrm{mmHg}$ dan akan di tampilkan pada LCD.

Pembagi tegangan pada alat ini digunakan untuk mengetahui besar kapasitas baterai yang digunakan, karena pada alat digunakan baterai 9 volt sebagai catu daya dan mikrokontroler, LCD, buzzer sendiri hanya membutuhkan 5 volt maka digunakan regulator 5 volt. Agar regulator bekerja secara maksimal dan pembacaan sensor menjadi stabil dibutuhkan tegangan input diatas 5 Volt apabila baterai sudah 6 volt maka akan ada pemberitahuan bahwa baterai sudah harus diganti.

\section{Titik Pengukuran}


Titik-titik yang akan diukur nilainya adalah sebagai berikut:

1. Titik pengukuran 1 (TP1) yaitu pada keluaran Baterai.

Untuk mengetahui besarnya tegangan pada baterai. Metode yang digunakan yaitu membandingkan nilai pada TP1 terhadap ground.

2. Titik pengukuran 2 (TP2) yaitu pada keluaran Regulator AMS1117.5

Untuk mengetahui besarnya tegangan keluaran IC AMS1117.5. Metode yang digunakan yaitu membandingkan nilai pada TP2 terhadap ground.

3. Titik pengukuran 3 (TP3) yaitu pada keluaran MPX5500DP

Untuk mengetahui besarnya tegangan keluaran pada sensor, yang mana $1 \mathrm{mmHg}=1,2 \mathrm{mVolt}$. Metode yang digunakan yaitu membandingkan nilai pada TP3 terhadap ground.

4. Titik pengukuran 4 (TP4) yaitu pada keluaran Pembagi Tegangan

Untuk mengetahui besarnya tegangan keluaran pada pembagi tegangan yang mana tegangan ini akan di teruskan pada pin adc mikrokontroler. Metode yang digunakan yaitu membandingkan nilai pada TP4 terhadap ground.

\section{Analisis Data}

Analisis data hasil pengukuran ini bertujuan untuk:

1. Membandingkan antara hasil menurut teori dan hasil ukur pada tiap-tiap titik pengukuran

2. Mengetahui besarnya persentase kesalahan (PK) pada tiap titik pengukuran

3. Mengetahui kemungkinan penyebab perbedaan antara hasil teori dan hasil ukur

Analisis data untuk masing-masing titik pengukuran adalah sebagai berikut:
1. Analisa TP1

TP1 merupakan keluaran baterai untuk sumber daya rangkaian. Secara teori, keluaran baterai 9 volt adalah tegangan DC 9 volt. Diketahui hasil ukur TP1 sebesar $9 \mathrm{~V}$ pada saat baterai masih penuh.

PK

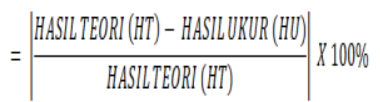

$$
\begin{aligned}
& P K=\left|\frac{9-9}{9}\right| X 100 \% \\
& P K=0 \%
\end{aligned}
$$

\section{Analisis TP2}

TP2 merupakan keluaran dari IC regulator AMS1117.5 untuk sumber daya sensor, rangkaian mikrokontroler, dan LCD. Menurut datasheet, IC AMS1117.5 mempunyai tegangan keluaran nilai minimal $4,85 \mathrm{~V}$, nilai tipikal $5 \mathrm{~V}$, dan nilai maksimal 5,15V. Diketahui hasil ukur TP2 sebesar 4,98 V, maka tegangan pada TP2 telah sesuai dengan datasheetAMS1117.5.

$$
\begin{aligned}
& \text { PK } \\
& =\left|\frac{\text { HASLLTEORI (HT) }- \text { HASLLUKUR (HU) }}{\text { HASSLTEORI(HT) }}\right| \text { X100\% } \\
& P K=\left|\frac{5-4,98}{5}\right| X 100 \% \\
& P K=0.4 \%
\end{aligned}
$$

\section{Analisis TP3}

TP3 merupakan keluaran sensor tekanan MPX5500DP yang berupa tegangan analog. Pengukuran dilakukan pada saat sensor mendapatkan tekanan udara dari luar sebesar 0, 50, 100, 150, 200, dan $250 \mathrm{mmHg}$. Nilai tekanan udara diubah satuannya dari $\mathrm{mmHg}$ menjadi $\mathrm{kPa}$ untuk dimasukan ke dalam rumus transfer function. Transfer Function adalah rumus untuk menentukan 
tegangan output sensor apabila diberi tekanan

tertentu.

Tabel 1. Hasil Analisis Titik Pengukuran 4 Berdasarkan Datasheet Sensor MPX5500DP

\begin{tabular}{cccccc}
\hline $\mathrm{P}(\mathrm{mmHg})$ & $\mathrm{P}(\mathrm{kPa})$ & Vout ukur $(\mathrm{mV})$ & Vout $(\mathrm{mV})$ & \multicolumn{2}{c}{ Toleransi $\pm 2,5 \%{ }^{*}$ Vout } \\
\cline { 4 - 6 } & & & & $\min$ & $\max$ \\
\hline 0 & 0,000 & 202,5 & 199,2 & 4,98 & 194,22 \\
\hline 50 & 6,667 & 265 & 258,96 & 6,474 & 252,486 \\
\hline 100 & 13,333 & 321,2 & 318,72 & 7,968 & 310,752 \\
\hline 150 & 20,000 & 380,4 & 378,48 & 9,462 & 369,018 \\
\hline 200 & 26,667 & 442 & 438,24 & 10,956 & 427,284 \\
\hline 250 & 33,333 & 500 & 498 & 12,45 & 485,55 \\
\hline
\end{tabular}

Setelah dilakukan penghitungan menggunakan rumus transfer function, didapatkan vout sensor untuk tekanan 0 sampai $250 \mathrm{mmHg}$ seperti yang tertera pada kolom berawarna kuning. Sedangkan hasil pengukuran vout sensor untuk tekanan 0 sampai $250 \mathrm{mmHg}$ tertera pada kolom warna biru.

\section{HASIL DAN PEMBAHASAN}

Bertempat di Laboratorium Prodi elektromedik telah dilakukan pengujian alat kalibrasi sphygmomanometer dengan FLUKE DPM 4. Dari hasil perbandingan dihitung rata-rata persentase error pembacaan tekanan dari alat kalibrasi sphygmomanometer. Hasil penghitungan error dapat di lihat pada Tabel 1

Tabel 2. Hasil Penghitungan Rata-Rata Error Pembacaan Tekanan Alat Kalibrasi Sphygmomanometer

\begin{tabular}{ccccc}
\hline Tekanan $(\mathrm{mmHg})$ & \multicolumn{2}{c}{ Rata-Rata } & $\begin{array}{c}\text { Selisih } \\
\text { Pengukuran }\end{array}$ & Error \% \\
\hline & $\begin{array}{c}\text { Alat Kalibrasi Fluke } \\
\text { DP4 }\end{array}$ & Alat Kalibrasi Baru & \\
\hline 0 & 0,00 & 0,00 & 0,00 & $0,0 \%$ \\
\hline 50 & 49,17 & 48,67 & 0,50 & $1,0 \%$ \\
\hline 100 & 98,83 & 99,00 & 0,17 & $0,2 \%$ \\
\hline 150 & 149,33 & 149,33 & 0,00 & $0,0 \%$ \\
\hline 200 & 199,50 & 200,00 & 0,50 & $0,3 \%$ \\
\hline 250 & 249,50 & 249,33 & 0,17 & $0,1 \%$ \\
\hline & & Rata-Rata Error & $0,3 \%$ \\
\hline
\end{tabular}

Untuk mendapatkan error pembacaan tekanan penulis membandingkan alat kalibrasi sphygmomanometer dengan Fluke DPM4 yang merupakan alat kalibrasi sphygmomanometer yang telah terkalibrasi.

Metode yang digunakan adalah pengukuran tekanan sphygmomanometer air raksa menggunakan alat kalibrasi sphygmomanometer dan alat kalibrasi fluke DPM4 yang disapasang secara paralel. Tekanan sphygmomanometer yang diukur adalah 0, 50, 100, 150, 200, dan $250 \mathrm{mmHg}$. Hasil pengukuran tekanan oleh alat kalibrasi fluke DPM4 dan alat kalibrasi baru ini akan dilihat selisih pengukuran tekanan antara dua alat tersebut kemudian dihitung presente error pembacaan tekanan oleh alat kalibrasi tugas akhir terhadap fluke DMP4.

Berdasarkan hasil wawancara dengan salah satu petugas kalibrasi BPFK (Balai Pengawasan Fasilitas Kesehatan) Solo, selisih pengukuran yang 
diperbolehkan pada alat kalibrasi sphygmomanometer terhadap kalibrator yang tertelusur adalah sebesar $1 \mathrm{mmHg}$.

Pada tabel 1 selisih pengukuran alat kalibrasi tugas akhir maksimal sebesar $0,5 \mathrm{mmHg}$ oleh karena itu dapat disimpulkan bahwa alat kalibrasi baru dapat digunakan dengan baik untuk mengkalibrasi sphygmomaometer air raksa.

\section{SIMPULAN DAN SARAN}

\section{Simpulan}

Setelah dilakukan seluruh tahap mulai dari pembuatan modul hingga pengukuran dan analisis, dapat diambil kesimpulan sebagai berikut:

1. Alat kalibrasi sphygmomanometer mampu mengukur tekanan sphygmomanometer dari 0 sampai dengan $300 \mathrm{mmHg}$.

2. Selisih pengukuran tekanan terhadap alat kalibrasi yang tertelusur maksimal sebesar 0,5 $\mathrm{mmHg}$, lebih kecil dari nilai toleransi pengukuran sebesar $1 \mathrm{mmHg}$.

3. Persentase kesalahan pengukuran tekanan sebesar $0.3 \%$

4. Alat dapat menentukan kelayakan sphygmomanometer air raksa berdasarkan hasil pengukuran kebocoran dan tekanan sphygmomanometer.

Saran

Program yang digunakan di dalam mikrokontroler hanya menghitung dalam satuan $\mathrm{mmHg}$. Untuk membuat alat dapat digunakan tidak hanya pada sphygmomanometer, satuan dapat dirubah menjadi kPa, Psi, Bar, atm dll.

\section{DAFTAR PUSTAKA}

Abdul Kadir. (2013). Panduan Praktis Mempelajari Aplikasi Mikrokontroler Dan Pemrogramannya Menggunakan Arduino. Yogyakarta: Andi Publisher.

Bagus Hari Sasongko. (2013). Pemrogaman Mikrokontroler Dengan Bahasa C. Yogyakarta. Andi Publisher.

C. Pearce Evelyn. (2009). Anatomi Dan Fisiologi Untuk Paramedic. Jakarta: PT. Gramedia Pustaka Utama.

Departemen Kesehatan. (2001). Pedoman Pengujian dan Kalibrasi Alat Kesehatan. Jakarta(ID). Depkes.

Pengenalan Tensimeter. (2015, Juni) [online].http://www.duniaalatkedokteran.com/20 10/10/pengenalan-tensimeter.html

Adc Accurate Readings. (2015, Juni) [online].http://hacking.majenko.co.uk/makingaccurate-adc-readings-on-arduinol 